\title{
Hesa-A Improves Clinical Outcome of Oral Carcinoma by Affecting p53 Gene Expression in vivo
}

\author{
Mehran Mesgari Abbasi ${ }^{1,2}$, Sanaz Helli ${ }^{3}$, Amir Monfaredan ${ }^{4}$, Rana Jahanban- \\ Esfahlan $^{2,5 *}$
}

\begin{abstract}
Background: Oral carcinoma (OC) remains as one of the most difficult malignancies to cure. Hesa-A is an Iranian herbal-marine compound that has shown promising anti-tumor properties on various human cancer cells, although the mechanisms of action remain to be addressed. This study was conducted to evaluate the effect of two doses of Hesa-A on mRNA expression of p53 as a main prognosticator of OC. Materials and Methods: 60 rats were randomly divided into 5 groups of 12 animals each. Rats in carcinoma groups received 0,250 and $500 \mathrm{mg} / \mathrm{kg}$ body weight of Hesa-A three times a day. The two other groups considered as treated and untreated healthy groups. At the end of experiment, animals were sacrificed and tongue tissues subjected to $H$ and $E$ staining and real time PCR. Results: Our results indicated that compared to healthy group, p53 over expressed $40 \%$ in untreated carcinoma group. After treatment with $250 \mathrm{mg} / \mathrm{kg}$ and $500 \mathrm{mg} / \mathrm{kg}$ body weights of Hesa-A, p53 level dropped by $53.4 \%$ and $13.6 \%$, respectively, compared to untreated carcinoma group $(p<0.05, p<0.0001)$. Moreover, there was a significant relation between p53 mRNA content and observed pathological changes in studied groups $(\mathbf{p}<0.05)$. Conclusions: These data provide insights into the mechanism(s) by which Hesa-A improves clinical outcome of oral carcinoma by modulation of p53 expression.
\end{abstract}

Keywords: Hesa-A - oral carcinoma - p53 expression - clinical outcome - rat model - oral doses

Asian Pac J Cancer Prev, 16 (10), 4169-4172

\section{Introduction}

Oral cavity cancers are rather common and rank eleventh among other cancers all over the world(Zwetyenga et al., 2003). Tongue cancer is the most common oral cavity neoplasm with an unfavorable prognosis and high metastatic potential(Abbasi et al., 2014d). Natural chemotherapeutic agents have always been acknowledged for their vast benefits and less side effects compared to the synthetic anti-neoplastic compounds(Valiyari $S$ et al., 2013). HESA-A is an Iranian patented new immunomodulating medication with natural biological compounds (Ahmadi et al., 2010b). Hesa-A is a mixture of herbal-marine substances and includes Penaeus latisculatus (king prawn), Carum carvi and Apium graveolens with antineoplastic properties(Ahmadi et al., 2010a).

Studies on anti-neoplastic properties of Hesa-A showed promising results in patients with advanced colorectal cancer and end staged breast cancer patients with choroidal metastasis (Ahmadi et al., 2005; Ahmadi et al., 2009). Analysis of the chemical composition of HESA-A has shown that it is composed of $50 \%$ inorganic substance, $45 \%$ organic substance (aminoenthraquinone) and $5 \%$ water. The inorganic component consists of calcium carbonate, magnesium phosphate and sulfate, potassium and sodium and elements such as aluminum, cobalt, potassium, chrome, iron, zinc, bromine and strontium at high concentrations(Mehdipour et al., 2013a).

The p53 gene is one of the most common studied biomarkers in OSCC. Functional inactivation of p53 causes defects in DNA repair and apoptosis, with a subsequent increase in genetic instability that may lead to the accumulation of mutations. The high expression of p53 has been associated with a poor prognosis and the combined expression of p53, cyclin D1, and EGFR has been correlated with an unfavorable prognosis in OSCC patients(Abusail et al., 2013; Abbasi et al., 2014b; Abbasi et al., 2014c) . Although Hesa-A showed satisfactory results in some end staged and metastatic tumors, however its effects need to be tested on other aggressive tumor types as well as oral carcinoma. Moreover, by far no study evaluated its effects at a molecular level to discern the possible underling mechanism of action.

Hence, in following study we evaluated the therapeutic effects of two oral doses of Hesa-A on p53 expression as a main prognosticator for oral cancer in an animal model of the disease.

${ }^{1}$ Drug Applied Research Center, ${ }^{2}$ Student Research Committee, ${ }^{3}$ Dental and Periodontal Research Center, ${ }^{5}$ Department of Medical Biotechnology, Faculty of Advanced Medical Sciences, Tabriz University of Medical Sciences, ${ }^{4}$ Department of Hematology, Faculty of Medicine, Tabriz,Branch Islamic Azad University, Tabriz, Iran *For correspondence: jahanbanr@tbzmed.ac.ir 


\section{Materials and Methods}

\section{Animals}

Sixty adult male Sprague Dawley rats (3-3.5 monthold) with an average weight of $220 \mathrm{~g}$ were obtained from the Animal Lab of Tabriz University of Medical Sciences. The animals were quarantined and acclimatized to laboratory conditions for 2 weeks. During the study, each rat was housed in a metal cage, with hardwood chips for bedding in an air-conditioned room under 12-h light/12-h dark cycles at a temperature of $22 \pm 2^{\circ} \mathrm{C}$. Detailed steps for 4-NQO induced oral cancer described by our group elsewhere(Mehdipour et al., 2013b; Abbasi et al., 2014a) .

\section{Hesa- A Preparation and administration to rats}

Hesa-A powder was dissolved for an hour in normal saline solution acidified with $\mathrm{HCl}$. The resultant solution was treated with $\mathrm{NaOH}$ to reach a final $\mathrm{pH}$ of 7.4. The solution was filtered and administered to rats by gavage three times a week at doses of 250 and $500 \mathrm{mg} / \mathrm{kg}$ body weights. Normal saline and 4NQO (30 ppm) were used as negative and positive controls, respectively. Sixty 12-week-old male Sprague Dawley rats were randomly divided into 5 groups of 12 animals each. Group i and ii served as carcinoma groups that received 500 and 250mg/ $\mathrm{kg}$ body weight doses of Hesa-A, respectively . Group (iii) served as untreated carcinoma group. Group (iv) served as the control and was fed on basic diet and tap water without 4-NQO and Group (v) served as healthy control that received $500 \mathrm{mg} \backslash \mathrm{kg}$ oral doses of Hesa-A three times a week (Table 1).

\section{RT-Real time PCR}

The Q- PCR was done according to our previous works(Jahanban Esfahlan et al., 2011a; Jahanban Esfahlan et al., 2011b; Jahanban Esfahlan et al., 2012). Briefly ,total RNA $(5 \mu \mathrm{g})$ extracted from homogenized fine powder of removed tongue tissues were reverse transcribed to cDNA using Revert Aid first strand cDNA synthesis kit (fermentase). The resulting cDNA was diluted 1:20 fold and the PCR reaction was performed with $2.5 \mu \mathrm{l}$ cDNA, $10 \mathrm{pM}$ each forward and reverse primers, $12.5 \mu 1 \mathrm{SYBR}$ Green PCR Master Mix (Fermentase) in a final volume of $25 \mu \mathrm{l}$. The thermal profile for the real-time Q-PCR was $95^{\circ} \mathrm{C}$ for $10 \mathrm{~min}$ and followed by 45 cycles of $95^{\circ} \mathrm{C}$ for 15 seconds and $60^{\circ} \mathrm{C}$ for $1 \mathrm{~min}$. Rat primers designed by Quant prime software as following : p53 (NM_030989.3): 5' - TCGAGATGTTCCGAGAGCTGAATG - 3' (forward), 5'-CTTCTTGGTCTTCGGGTAGCTG -3' (reverse). GAPDH (AF 106860): 5'-ATGACTCTAC CCACGGCAAG-3' (forward), 5'-CTGGAGATGG
TGATGGGTT-3' (reverse).

The gene expression was expressed as fold change from the GAPDH level which is calculated as $2-\Delta \Delta \mathrm{Ct}$. Following, fold changes expressed as percents by following formula :

\section{Fold change $($ percent $)=$ fold change $\times 100$}

\section{Ethics}

All the ethical and the humanity considerations were performed according to the Helsinki humanity research declaration during the experiments and the euthanasia of the animals. All the animals' experiments were approved by the Ethics Committee of the Tabriz University of Medical Sciences.

\section{Data analyses}

The data were analyzed using SPSS No 16. One-Way Analysis Of Variance (ANOVA) was used to compare fold change difference in groups followed by multiple comparisons with the LSD post-hoc test. Chi square test was used to evaluate relation between p53 content and pathological changes. $\mathrm{p}$ value $<0.05$ was considered significant.

\section{Results}

Histopathological changes in studied groups

After 12 weeks treatment with 4NQO, precancerous lesions in the oral cavity including hyperplasia and different types of dysplasia were detectable. Almost all the rats in carcinoma group displayed hyperplasia followed by all types of dysplasia. Histopathologial changes in studied groups were as following:

Group I (Untreated carcinoma group) which was treated with 4NQO showed (0\9) normal, $1 \backslash 9$ hyperplasia and $8 \backslash 9$ dysplasia .

In Group II (Hesa -A 250mgไkg + 4NQO): 2\11 of lesions were normal , 3\11 hyperplasia and 5\11 showed dysplasia.

In Group III (Hesa -A 500mg $\backslash k g+4 \mathrm{NQO}$ ): $3 \backslash 10$ of lesions were normal, $3 \backslash 10$ were hyperplasia and $3 \backslash 10$ showed different stages of dysplasia including mild, moderate and severe dysplasia.

All cases in Group IV and V (Healthy controls) displayed a normal histology in examination (12\12) (Fig1). There was no significant difference between healthy group and healthy group which was treated with $500 \mathrm{mg} / \mathrm{kg}$ body weight of Hesa-A ( $\mathrm{p}>0.05)$. Pathological changes significantly were found to be different between carcinoma group and Hesa-A treated carcinoma groups $(\mathrm{P}<0.01)$.

Table 1. Characteristics of the Experimental Groups in this Study

\begin{tabular}{|c|c|c|c|c|c|}
\hline Experimental Groups & $\begin{array}{l}\text { Names of } \\
\text { Groups }\end{array}$ & $\begin{array}{l}\text { Sort of } \\
\text { treatment }\end{array}$ & $\begin{array}{l}\text { Number of } \\
\text { total cases }\end{array}$ & $\begin{array}{c}\text { Number of } \\
\text { examined cases }\end{array}$ & $\begin{array}{c}\text { Number of } \\
\text { dead cases(n) }\end{array}$ \\
\hline \multirow[t]{3}{*}{ Carcinoma Groups } & $\mathrm{i}$ & 4-NQO & 12 & 12 & 0 \\
\hline & ii & 4-NQO+250 mg/kg HESA-A & 12 & 12 & 0 \\
\hline & iii & 4-NQO+500 mg/kg HESA-A & 12 & 9 & 3 \\
\hline Healthy & iv & None & 12 & 11 & 1 \\
\hline Groups & $\mathrm{V}$ & $500 \mathrm{mg} / \mathrm{kg}$ HESA-A & 12 & 10 & 2 \\
\hline
\end{tabular}


Effect of Hesa-A on mRNA expression of P53 in rat tongue tissues

p53 mRNA expression in groups quantified by Real time PCR. Results indicated that compared to healthy group, p53 over expressed $\sim 40 \%$ in untreated carcinoma group $(\mathrm{p}<0.05)$ (data not shown). Moreover, quantification of p53 mRNA showed that compared to untreated carcinoma (iii) , treatment of carcinoma groups (iv) and (v) with two oral doses of Hesa-A ( 250mg/ $/ \mathrm{kg}$ and $500 \mathrm{mg} /$ $\mathrm{kg}$ per body weight) resulted in $53.4 \%$ and $13.6 \%$ decrease in p53 level, respectively that was statistically significant $(\mathrm{P}<0.05, \mathrm{p}<0.0001)$. Dose $500 \mathrm{mg} / \mathrm{kg}$ of Hesa-A decreased p53 mRNA $\sim 5$ folds more than dose $250 \mathrm{mg} / \mathrm{kg}(\mathrm{p}<0.01)$. Furthermore, p53 was not detectable in either of healthy control and healthy control that was treated with $500 \mathrm{mg}$ $/ \mathrm{kg}$ of Hesa-A ( $>>0.05)$. Observed \% mRNA changes in studied groups shown in figure 2 .

Relation between p53 mRNA and pathological changes in samples

As shown in Table 2 and Table 3 , our results indicated that in group treated with $500 \mathrm{mg} / \mathrm{kg}$ body weight of Hesa-A, all 3\3(100\%) normal lesions expressed low mRNA level or undetectable amounts of p53 similar to that of healthy groups $(\mathrm{p}>0.05)$ whilst in hyperplasia lesions, $1 \backslash 3(33.3 \%)$ showed a low level of p53 level and $2 \backslash 3(66.7 \%)$ represent high amount of p53 mRNA and $3 \backslash 3(100 \%)$ of dysplasia lesions expressed a high level of p53 (P=0.043).

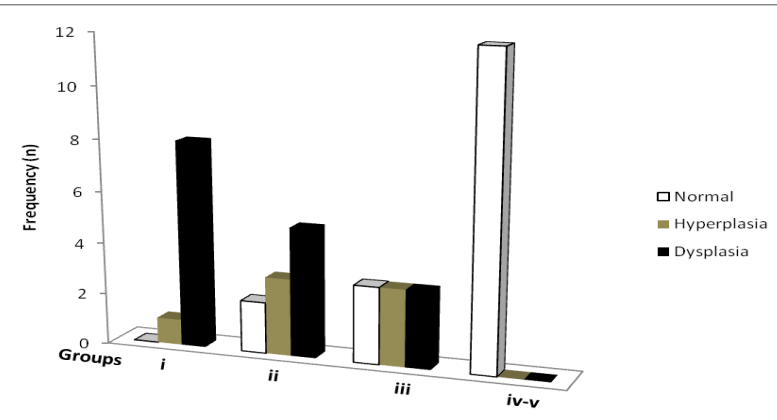

Figure 1. Frequency of Observed Pathological Changes in Groups

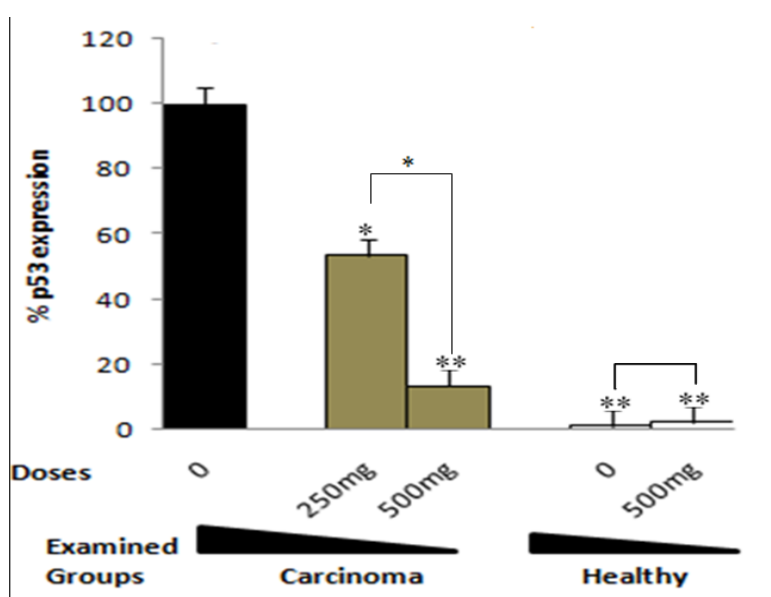

Figure 2. Effect of two doses of Hesa -A on p53 Expression in Rat Model of Oral Carcinoma
DOI:http://dx.doi.org/10.7314/APJCP.2015.16.10.4169

The Effect of Hesa-A on p53 Expression in Oral Carcinoma

Table 2. Rrelation between p53 mRNA Expression and Tumor Stage in Carcinoma Group Treated with Oral doses of $500 \mathrm{mg} / \mathrm{kg}$ HESA-A

\begin{tabular}{llrrr}
\hline $500 \mathrm{mg} / \mathrm{kg}$ HESA-A & \multicolumn{3}{c}{ P53 mRNA (P=0.043) } \\
& & \multicolumn{1}{c}{ Low } & Moderate\High & Total \\
\hline Tumor stage & Normal & $3(100 \%)$ & $0(0.0 \%)$ & $3(100 \%)$ \\
& Hyperplasia & $1(33.3 \%)$ & $2(66.7 \%)$ & $3(100 \%)$ \\
& Dysplasia & $0(0.0 \%)$ & $3(100.0 \%)$ & $3(100 \%)$ \\
& Total & $4(44.4 \%)$ & $5(55.6 \%)$ & $9(100 \%)$ \\
\hline
\end{tabular}

Table 3. Relation between p53 mRNA Expression and Tumor Stage in Carcinoma Group that Treated with Oral doses of $250 \mathrm{mg} / \mathrm{kg}$ HESA-A

\begin{tabular}{|c|c|c|c|}
\hline \multicolumn{2}{|c|}{$250 \mathrm{mg} / \mathrm{kg}$ HESA-A } & \multicolumn{2}{|c|}{$\mathrm{P} 53$ mRNA $(\mathrm{P}=0.027)$} \\
\hline & & low ModeratelHigh & h Total \\
\hline \multirow{4}{*}{$\begin{array}{l}\text { Pathological } \\
\text { changes }\end{array}$} & Norm & $2(100.0 \%) \quad 0 \quad(0 \%)$ & $2(100 \%)$ \\
\hline & Hyperplasia & $2(66.7 \%) 1(33.3 \%)$ & $3(100 \%)$ \\
\hline & Dysplasia & $\begin{array}{lll}0 & (0.0 \%) & 5(100 \%)\end{array}$ & $5(100 \%)$ \\
\hline & Total & $4(40.0 \%) 6(60 \%)$ & $10(100 \%)$ \\
\hline
\end{tabular}

In group that was given $250 \mathrm{mg} / \mathrm{kg}$ oral doses of Hesa-A, results showed that all $2 \backslash 2(100 \%)$ normal lesions expressed low mRNA level of p53 whilst in hyperplasia lesions, $2 \backslash 3(66.7 \%)$ showed a high level of p53 level and $1 \backslash 3(33.3 \%)$ represent low amount of p53 mRNA and $5 \backslash 5(100 \%)$ of dysplasia lesions expressed a high level of p53 $(\mathrm{P}=0.027)$.

\section{Discussion}

Oral cancers, the vast majority of which are comprised of squamous cell carcinomas (SCCs), are among the ten top common cancers worldwide(Abbasi et al., 2014c). In spite of extensive treatment (surgery, radiotherapy and/ or chemotherapy), OSCC is associated with recurrence and second primary tumors that are responsible for poor overall survival rates $(\sim 50 \%)$ which is not improved significantly over the past three decades which urgent the need for search and development of new effective treatments(Zwetyenga et al., 2003; Abbasi et al., 2014b).

HESA-A is an Iranian patented natural product with a herbal/marine origin which is showed to possess beneficial anti-tumor effects on some types of aggressive tumors.

Ahmadi et al in 2005 tested the effects of $50 \mathrm{mg} / \mathrm{kg} /$ day of Hesa-A on 24 end staged breast cancer patients with retina choroid metastases. Their findings indicated that $92 \%$ of the patients who received HESA-A at a dosage of $50 \mathrm{mg} / \mathrm{kg}$ /day orally lived with notably improving quality of life through the six months of the study. These patients suffered fewer complications and survived longer(Ahmadi et al., 2005).

In the second study by Ahmadi et al in 2009, authors investigated therapeutic effects of Hesa-A in fifty consecutive patients with end-stage colon cancer and liver metastasis. Patients received Hesa-A $50 \mathrm{mg} / \mathrm{kg} / \mathrm{d}$ orally in 2 to 3 divided doses for 6 months. The authors concluded that Hesa-is an effective and safe anticancer drug, in treatment of selected patients with less side effects(Ahmadi et al., 2009).

In another clinical trial study by Ahmadi et al in 2010, 
thirty consecutive patients ( 18 men, 12 women) with endstage cancers and liver metastasis were studied. Patients received Hesa-A $50 \mathrm{mg} / \mathrm{kg} / \mathrm{d}$ orally in 2 to 3 divided doses for 3 months. Result showed that a total of $90.4 \%$ of the patients who remained in the study were alive for 12 weeks. No significant hepatic or hematologic adverse effect was seen during the study(Ahmadi et al., 2010b).

In 2013, Mehdipour et al evaluated the effect of two systemic doses of Hesa-A on prevention of induced tongue neoplasm in rats. Their results indicated that Hesa-A has dose-dependent inhibitory effects on the development of neoplasms of the tongue(Mehdipour et al., 2013a).

In a recent study, Muhammmadnejad et al assessed selective growth inhibitory effects of Hesa-A on breast (MCF-7), prostate (PC3), colon (HCT-116) and glioblastoma multiforme (U-87MG) neoplastic cell lines .They indicated that HESA-A at the highest concentration $(100 \mu \mathrm{g} / \mathrm{mL})$ significantly inhibited the growth of HCT-116 cell line (40.13\% growth inhibition) and no satisfactory results obtained by the other tested cell lines(Muhammmadnejad et al., 2014). However, our unpublished data showed that dose $0.4 \mathrm{mg} / \mathrm{ml}$ of Hesa-A possess potent cytotoxic effects on different human cell lines as well as MCF-7, PC3.

Varying percentages of oncogenes expressed in oral tumors and p53 suppressor gene is undoubtedly the most studied one , expressed from $4 \%$ to $50 \%$, as in our study ,p53 overexpressed $\sim 40 \%$ in untreated carcinoma group . High expression of p53 has been associated with a poor prognosis in oral and other aggressive cancers.

In agreement with findings of Ahmadi et al , the results of our study indicated that in addition to colon cancer and end staged breast cancer, Hesa-A could be effective in treatment of tongue neoplasm which is the most aggressive tumor of oral cavity with poor prognosis. Moreover, two doses of Hesa-A were able to affect expression of p53 in treated carcinoma group and this observation showed a dose dependant manner, as dose $500 \mathrm{mg} / \mathrm{kg}$ body weight showed superior activity in decreasing p53 mRNA level in oral neoplasms. Moreover, in groups that were treated with different doses of Hesa-A, decreased expression of p53 was related with improved clinical outcome. No pathological changes observed in healthy group that was treated with $500 \mathrm{mg} / \mathrm{kg}$ of Hesa-A which in turn indicate to the safety of compound. Altogether, anti tumor properties of Hesa-A on oral carcinoma confirms the results of previous studies which introduce Hesa-A as an effective chemotherapeutic agent in treatment of aggressive tumors with less side effects on normal cells and following put forwards p53 pathway as a putative mechanisms of action for anti neoplastic properties of this Herbal- Marin originated compound on human cancers.

In conclusion, p53 over expression is an important hallmark of tumor aggressiveness and poor prognosis in different types of tumor as well as oral carcinoma . Significant decrease in level of this prognosticator factor that as accompanied by improvement of pathological lesions in oral carcinoma implies that affecting p53 pathway could be considered as a mechanism of action for potent anti tumor activities of Hesa-A extract on different progressive human malegnancies including oral carcinoma. .

\section{References}

Abbasi MM, Jahanban-Esfahlan R, Monfaredan A, et al (2014a). Oral and IV dosages of doxorubicin-methotrexate loadednanoparticles inhibit progression of oral cancer by downregulation of matrix methaloproteinase 2 expression in vivo. Asian Pac J Cancer Prev, 15, 10705-11.

Abbasi MM, Khiavi MM, Monfaredan A, et al (2014b). DOXMTX-NPs augment p53 mRNA expression in OSCC model in rat: effects of IV and oral routes. Asian Pac J Cancer Prev, 15, 8377-82.

Abbasi MM, Monfaredan A, Hamishehkar H, et al (2014c). New formulated "DOX-MTX-loaded nanoparticles" downregulate HER2 gene expression and improve the clinical outcome in OSCCs model in rat: the effect of IV and oral modalities. Asian Pac J Cancer Prev, 15, 9355-60.

Abbasi MM, Monfaredan A, Hamishehkar H, et al (2014d). Novel DOX-MTX nanoparticles improve oral SCC clinical outcome by down regulation of lymph dissemination factor VEGF-C expression in vivo: oral and IV modalities. Asian Pac J Cancer Prev, 15, 6227-32.

Abusail M, Dirweesh AM, Salih RA, et al (2013). Expression of EGFR and p53 in head and neck tumors among sudanese patients. Asian Pac J Cancer Prev, 14, 6415-8

Ahmadi A, Habibi G, Farrokhnia M (2010a). Anticancer effects of HESA-A: An herbal marine compound. Chin J Integr Med, 16, 366-7.

Ahmadi A, Mohagheghi M, Karimi M, et al (2009). Anticancer effects of HESA-A in patients with metastatic colon cancer. Integr. Cancer Ther, 8, 71-4.

Ahmadi A, Mohagheghi M, Karimi M, et al (2010b). Therapeutic effects of HESA-A in patients with end-stage metastatic cancers. Integr. Cancer Ther, 9, 32-5.

Ahmadi A, Mohagheghi MA, Fazeli MS, et al (2005). HESA-A: new treatment for breast cancer and choroidal metastasis. Med Sci Monit, 11, 300-3.

Jahanban Esfahlan R, Zarghami N, Jahanban Esfahlan A, et al (2011a). The possible impact of obesity on androgen, progesterone and estrogen receptors (ERa and $\mathrm{ERb}$ ) gene expression in breast cancer patients. breast cancer (Auckl), 227-37.

Jahanban Esfahlan R, Zarghami N, Rahmati-Yamchi M, et al (2011b). Quantification of steroid receptors gene expression in breast cancer patients: possible correlation with serum level of adipocytokines. J Cancer Therapy, 2, 659-65.

Jahanban Esfahlan R, Zarghami N, Valiyari S, et al (2012). Adiponectin can affect ER signaling in obese breast cancer patients. J Cancer Therapy, 3, 115-21

Mehdipour M, Taghavi Zenouz A, Mesgari Abbasi M, et al (2013b). Evaluation of the effect of two systemic doses of HESA-A on prevention of induced tongue neoplasm in rats. J Dent Res Dent Clin Dent Prospects, 7, 218-24.

Muhammmadnejad S, Zendehdel K, Mazaheri Z, et al (2014). Assessment of selective growth inhibitory effects of HESA-A on some human neoplastic cell lines. Breast Cancer: Basic and Clinical Res, 6.

Valiyari S, Jahanban-Esfahlan R, Zare Shahneh F, et al (2013). Cytotoxic and apoptotic activity of Scrophularia oxysepala in MCF-7 human breast cancer cells. Toxicol Environmental Chem, 95, 1208-20.

Zwetyenga N, Majoufre-Lefebvre C, Siberchicot F, et al (2003). [Squamous-cell carcinoma of the tongue: treatment results and prognosis]. Rev Stomatol Chir Maxillofac, 104, 10-7. 